\title{
Invertebrate communities in holdfasts of the kelp Macrocystis pyrifera from southern Chile
}

\author{
F. P. Ojeda and B. Santelices \\ Departamento de Biología Ambiental y de Poblaciones, Facultad de Ciencias Biológicas, Pontificia Universidad Católica de \\ Chile, Casilla 114-D, Santiago, Chile
}

\begin{abstract}
Forty-two taxa of invertebrates and 1 species of fish were found in holdfasts of Macrocystis pyrifera in the giant kelp forest in Puerto Toro, Navarino Island, southern Chile. Maximum values of invertebrate density and biomass occur in late winter and spring, while higher values of species richness and diversity $\left(\mathrm{H}^{\prime}\right)$ are found in winter. Quantitative data indicate that 4 species (Pseudechinus magellanicus, Pagurus forceps, Halicarcinus planatus, Anasterias antarctica) are the determinant taxa in the overall changes of invertebrate biomass and density. Data on body size and average weight of these species indicate that neither growth nor juvenile recruitment are responsible for the overall pattern of change. Migration behavior of these species is a more likely explanation. The rate of accumulation of species of invertebrates to the holdfast is fast in small holdfasts, very slow in larger holdfasts, and the pioneer species are also found in larger and older holdfasts. Thus, the dynamic of species turn over does not follow a species replacement series typical of colonization processes described for non-growing habitats.
\end{abstract}

\section{INTRODUCTION}

Most of the studies describing invertebrate microand macrofauna in holdfasts of brown algae have a clear taxonomic trend (Colman, 1940; Ghelardi, 1960; Scorrat, 1961; Moore, 1971, 1973a; Quast, 1971). Only occasionally have the ecological interactions of the invertebrate communities occurring in the holdfasts been analysed or even described (Jones, 1971, 1972, 1973; Moore, 1972, 1973b, c, 1974, 1978). The knowledge of the fauna inhabiting holdfasts of Macrocystis pyrifera is not an exception to this trend. Although Ghelardi (1971) exhaustively described the structure of invertebrate communities occurring in the holdfasts of $M$. pyrifera in California, he neither mentioned the ecological role(s) of holdfasts with respect to their invertebrate fauna, nor described temporal or spatial changes in the structure of such communities.

Ecological knowledge of the invertebrate fauna inhabiting holdfasts of Macrocystis pyrifera elsewhere is still more limited. A diversity of invertebrates occurs in the holdfasts of $M$. pyrifera in southern South America (Dayton, 1974; Barrales and Lobban, 1975) but almost any aspect of their biology other than taxonomy is completely unknown.

The general roles played by holdfast of algae and especially by kelp-like Phaeophyta with respect to the fauna which inhabits them include those of mechanical shelter (wave impact), refuge from predators, and nursery grounds (Andrews, 1945; Bayne, 1964; Wigham, 1975; Moore, 1978; Cancino and Santelices, 1981). Such roles have been described mostly for invertebrates occurring in kelp holdfasts which, being relatively compact, maintain a community structure which can sometimes be quantitatively different from that existing outside the holdfasts. Furthermore, there is some evidence that the invertebrate community occurring in Phaeophyta holdfasts might also develop a pattern of invasion of the holdfast (Cancino and Santelices, 1981) qualitatively different to colonization processes described for non-growing habitats (Connell and Slatyer, 1977); in other words, colonization of holdfasts might change dramatically as the holdfasts grow in size and complexity.

The present study describes the community structure of invertebrates inhabiting holdfasts of Macrocystis pyrifera in subtidal forests of southernmost Chile (Beagle Channel zone) and their quantitative relationships with some morphological variables of the holdfasts. On this basis we compare invertebrate communities associated to $M$. pyrifera holdfasts in the northern and southern hemispheres. In addition, 
through seasonal sampling, we report in this study the temporal modifications of the fauna inhabiting holdfasts. Simultaneously, and on the basis of the temporal changes in population structure of the most important species, we evaluate the ecological roles of the brown algal holdfasts, in relation to the fauna inhabiting them. Finally, qualitative and quantitative descriptions are given of the general dynamics of holdfast occupation by invertebrates.

\section{MATERIALS AND METHODS}

The material studied was collected in the forests of Macrocystis pyrifera surrounding Puerto Toro, at Navarino Island $\left(53^{\circ} 07^{\prime} \mathrm{S} ; 72^{\circ} 00^{\prime} \mathrm{W}\right)$, Chile. A detailed description of the $M$. pyrifera beds occurring in this site has been given by Santelices and Ojeda (1983).

A total of 62 holdfasts from the coastal belt of Macrocystis pyrifera were examined among 5 seasonal samplings, throughout a 1 yr study. Twelve holdfasts were collected in September and 14 in November, 1979; 15 were collected in January, 12 in April and 9 in June, 1980. Collections were performed by 2 SCUBA divers. Each holdfast was first detached from the substrate by means of a mechanical lever, and placed in labelled plastic bags, in order to avoid loss of animals. The stipes of the plant were then cut off, the plastic bag closed and transported to the surface. In each collection, special care was taken to sample holdfasts throughout the width of the $M$. pyrifera bed including specimens of various sizes. A morphometric analysis of these populations of $M$. pyrifera is given by Santelices and Ojeda (1983).

The holdfasts and their associated fauna were fixed in a $10 \%$ formaldehyde solution diluted in sea water and transported to the laboratory for analysis. Holdfasts were measured, weighed and dissected. The invertebrates were identified whenever possible to species, counted, measured with a caliper to $0.1 \mathrm{~mm}$ accuracy and weighed wet in a Sartorius balance with $0.1 \mathrm{mg}$ accuracy. The size was estimated by the carapace length for decapod crustaceans and by test diameter of the ambitus for sea urchins.

Species richness and diversity of each sample was calculated by the number of species per holdfast, the relative abundance of the animals and the ShannonWeaver index. Since size (and biomass) of the holdfast increases as it grows, we tried to standardize the values of relative abundance of invertebrates in the holdfasts in order to compare invertebrate abundance among holdfasts with different sizes and collected at different times of the year. Thus, an index of abundance was calculated as the ratio of invertebrate biomass to holdfast biomass times 100 . One-way
ANOVA was employed for the detection of changes in temporal patterns of biomass, density, and richness of species in the holdfasts (Sokal and Rholf, 1969).

\section{RESULTS}

\section{Structure of the invertebrate community associated with holdfasts}

A total of 43 taxa representing 6 phyla was recognized in the holdfasts of Macrocystis pyrifera (Table 1). With the exception of 1 fish species (Notothenia cornucola) the inhabitants of the holdfasts were invertebrates, mostly crustaceans, echinoderms, and molluscs. Of the total taxa inhabiting holdfasts of $M$. pyrifera, 4 species account for about $63.3 \%$ of the total density and biomass (Table 2). Of these, Pseudechinus magellanicus is the dominant species in density and biomass, followed by Pagurus forceps, Anasterias antarctica and Halicarcinus planatus. A number of polychaete species, grouped together, also were important in both density and biomass.

The overall biomass of invertebrates is a function of the volume, weight and height of the holdfast (Fig. 1). In turn, number of taxa, diversity $\left(\mathrm{H}^{\prime}\right)$ and total number of individuals are logarithmically correlated with the volume of the holdfast (Fig. 2). This type of relationships indicates that species richness, diversity and total number of individuals increase rapidly with the size of the holdfasts up to about $2000 \mathrm{~cm}^{3}$ of holdfast volume. The increment of these parameters in holdfasts with volumes larger than $2000 \mathrm{~cm}^{3}$ is very slow. These results indicate that below $2000 \mathrm{~cm}^{3}$ holdfasts seem unsuited for some species, perhaps because of size restrictions to large-sized occupants. Above that size all invertebrate species available to occupy the holdfast can do so, and as the holdfast increases in size invertebrate biomass increases both by growth of the invertebrates and by slight increments in the number of individuals of different species in the holdfasts. The fact that diversity values $\left(\mathrm{H}^{\prime}\right)$ remain constant in holdfasts with volume values above $2000 \mathrm{~cm}^{3}$ (Fig. 2) indicate that the increments in density affects more or less homogeneously most species in the holdfasts.

\section{Temporal variations in community structure}

A temporal comparison of the invertebrates biomass values (Fig. 3) shows that in spring (September and November, 1979) the abundance of invertebrates in holdfasts of Macrocystis pyrifera was significantly greater than in other seasons (one-way ANOVA: $F=9.20 p<0.001 ;$ critical $\left.F_{4,56}[\alpha=0.01]=3.75\right)$. 
Table 1. Taxa found in 62 holdfasts of Macrocystis pyrifera from Puerto Toro, Navarino Island

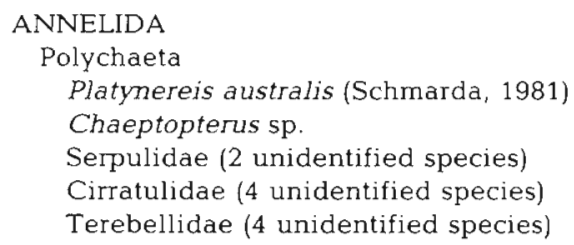

NEMERTEA (unidentified)

\section{MOLLUSCA}

Bivalvia

Aulacomya ater (Molina, 1782)

Gastropoda

Nacella mytilina (Helbling, 1779)

Margarella violacea (King \& Broderip, 1831)

Paraeuthria plumbea (Philippi, 1944)

Trophon laciniatus (Martyn, 1789)

Crepipatella dilatata (Lamarck, 1822)

Ximenopsis falklandicus (Strebel 1908)

Paraeuthria ringei (Strebel 1905)

Pareuthria sp.

Fissurella spp.

Cerithiopsis sp.

Amphineura (2 unidentified species)

\section{ARTHROPODA (CRUSTACEA)}

Decapoda

Halicarcinus planatus (Fabricius, 1775)

Paralomis granulosa (Jaquinot, 184?)

Nauticaris magellanica (H. Milne Edwards, 1888)

Betaeus truncatus Dana, 1852

Pagurus forceps (H. Milne Edwards, 1836)

Munida subrugosa (White, 1847)

Campylonotus vagans (Bate, 1888)

Isopoda

Crassidinopsis emarginata (Guerin-Meneville, 1843)

Exosphearona studeri Vanhoffen, 1914

Dynamenella eatoni (Miers, 1875)

Phycolimnoria sp.

Amphipoda

Gammaridae (3 unidentified species)

Eusiridae (2 unidentified species)

Amphithoidae (1 unidentified species)

\section{ECHINODERMATA}

Echinoidea

Pseudechinus magellanicus (Philippi, 1857)

Austrocidaris canaliculata (A. Agassiz, 1863)

Asteroidea

Patiriella fimbriata (Perrier, 1876)

Patiria obesa (Clark, 1910)

Odontaster penicillatus (Philippi, 1870)

Porania antarctica Smith, 1876

Anasterias antarctica (Lutken, 1856)

Ophiuroidea

Ophiactis asperula (Philippi, 1858)

Ophiocteas camosus Lyman, 1879

\section{CHORDATA}

Ascidiacea

Styela melincae Arnback, 1929

Osteichthyes

Notothenia comucola Richardson, 1845

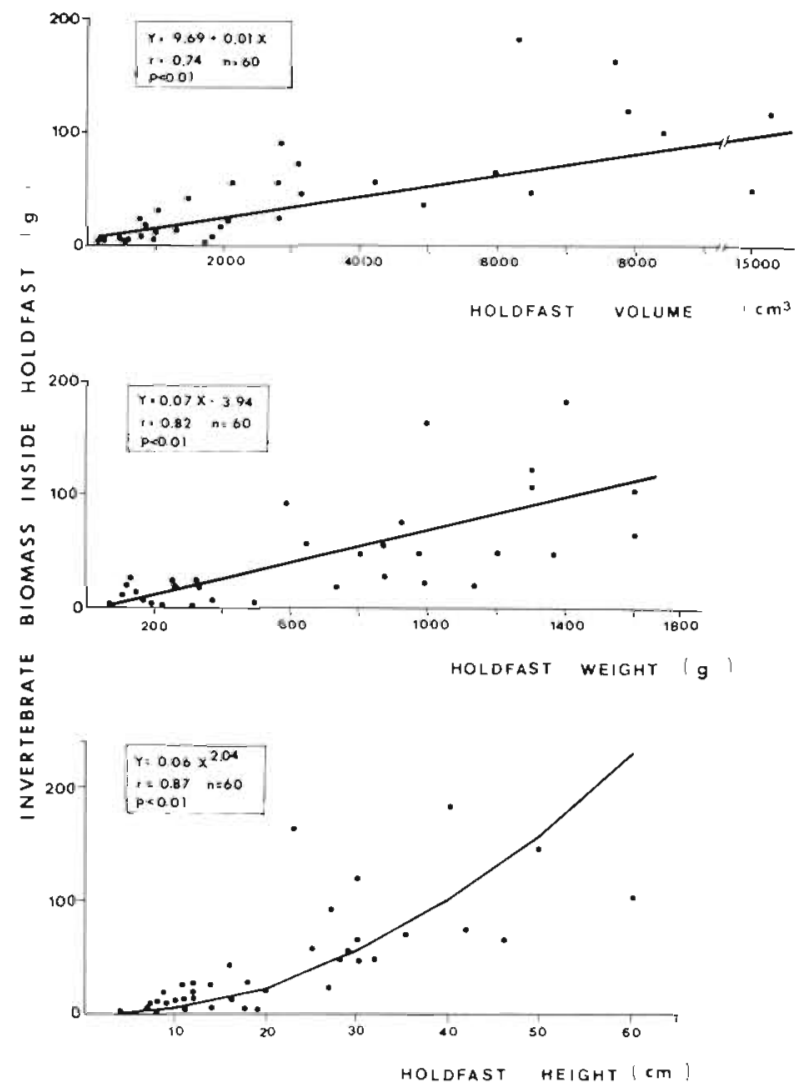

Fig. 1. Macrocystis pyrifera. Relationships between invertebrate biomass and 3 morphological dimensions of the holdfast in populations from Puerto Toro, Navarino Island, southern Chile

Lesser values of abundance were found in summer (January, 1980) and intermediate values occurred in autumn and winter (April and July, 1980). No significant differences were found among them. These results suggest a temporal phenomenon of invertebrate concentrations towards the holdfast in late winter and early spring, withdrawal from the holdfast during summer and slow return in autumn and early winter.

A similar process of changes was observed when analysing temporal variations in number of organisms in the holdfasts (Fig. 3). In spring, the density was significantly higher (one-way ANOVA, $F=9.31$ $p<0.001$; critical $F_{4.56}[\alpha=0.01]=3.75$ ) with respect to other seasons, and a marked reduction in the density of holdfast was observed in summer.

As to the values of richness and diversity of species, temporal changes showed a somewhat different pattern. Number of species was significantly higher in winter, as compared to summer (one-way ANOVA, F $=7.98 \mathrm{p}<0.001_{i}$ critical $\left.F_{4,56}[\alpha=0.01]=3.75\right) \mathrm{a}$ pattern closely resembling that observed for species diversity. This suggests that temporal changes in biomass and density affect in a different way the diffe- 
Table 2. Ranking of the relative importance of invertebrate taxa found in 62 holdfasts of Macrocystis pyrifera from Puerto Toro, Navarino Island. Relative importance values are based on values of biomass and density for each species

\begin{tabular}{|c|c|c|c|c|c|c|}
\hline Taxa & Biomass $(g)$ & $\%$ & Rank & No individuals & $\%$ & Rank \\
\hline Pseudechinus magellanicus & 675.77 & 42.8 & 1 & 910 & 20.8 & 1 \\
\hline Polychaeta (various species) & 175.52 & 11.1 & 2 & 789 & 18.0 & 3 \\
\hline Pagurus forceps & 113.53 & 7.2 & 3 & 909 & 20.7 & 2 \\
\hline Anasterias antarctica & 111.16 & 7.0 & 4 & 141 & 3.2 & 5 \\
\hline Halicarcinus planatus & 99.96 & 6.3 & 5 & 474 & 10.8 & 4 \\
\hline Notothenia cornucola & 80.76 & 5.1 & 6 & 23 & 0.5 & 17 \\
\hline Fissurella spp. & 54.01 & 3.4 & 7 & 124 & 2.8 & 7 \\
\hline Nemertea (indet.) & 49.06 & 3.1 & 8 & 25 & 0.6 & 16 \\
\hline Paraeuthria plumbea & 36.19 & 2.3 & 9 & 69 & 1.6 & 13 \\
\hline Patiriella fimbriata & 26.31 & 1.7 & 10 & 140 & 3.2 & 6 \\
\hline Crepipatella dilatata & 21.14 & 1.3 & 11 & 101 & 2.3 & 9 \\
\hline Austrocidaris canaliculata & 20.94 & 1.3 & 12 & 18 & 0.4 & 18 \\
\hline Margarella violacea & 17.11 & 1.1 & 13 & 85 & 1.9 & 11 \\
\hline Ophiuroids (various species) & 15.07 & 0.9 & 14 & 28 & 0.6 & 15 \\
\hline Other decapods (various species) & 12.80 & 0.8 & 15 & 83 & 1.9 & 12 \\
\hline Paralomis granulosa & 11.02 & 0.7 & 16 & 2 & 0.1 & 20 \\
\hline Odontaster penicillatus & 10.93 & 0.7 & 17 & 2 & 0.1 & 20 \\
\hline Isopods (various species) & 8.87 & 0.6 & 18 & 53 & 1.2 & 14 \\
\hline Aulacomya ater & 7.13 & 0.4 & 19 & 121 & 2.8 & 8 \\
\hline Nacella mytilina & 5.97 & 0.4 & 20 & 18 & 0.4 & 18 \\
\hline Paraeuthria sp. & 5.93 & 0.4 & 21 & 93 & 2.1 & 10 \\
\hline Trophon spp. & 4.01 & 0.3 & 22 & 10 & 0.2 & 19 \\
\hline Chitons (various species) & 1.73 & 0.1 & 23 & 69 & 1.6 & 13 \\
\hline Amphipods (various species) & 1.18 & 0.1 & 24 & 25 & 0.6 & 16 \\
\hline
\end{tabular}

rent invertebrate taxa which invade the holdfast or emigrate from it in different proportions.

An analysis of the temporal variations of biomass and density showed that there are 5 taxa which maintain the highest biomass values throughout the year. As a whole, such species represent over $75 \%$ of the biomass. These 5 taxa have different patterns of temporal representation (Fig. 4). Among them, Pseudechinus magellanicus is the only one presenting a clear-cut temporal variation in abundance, primarily determined by a maximum value in late spring (November, 1979), which is significantly higher than those of the rest of the year (one-way ANOVA; $F$. = $4.72 \mathrm{p}<0.01$ critical $\mathrm{F}_{4,56}[\alpha=0.01]=3.75$ ). This pattern of variation is similar to that found for the total values of invertebrates biomass, demonstrating the importance of $P$. magellanicus in the overall biomass. The remaining 4 taxa, have no clear significant patterns of temporal variations with respect to biomass abundance (Fig. 4). It is important to notice, however, that Pagurus forceps shows an evident although statistically not significant biomass increment during November.

The analysis of temporal variations in densities of the 5 taxa (Fig. 4) disclosed a pattern of variation similar to biomass. In this case, however, both Pseudechinus magellanicus and Pagurus forceps showed temporal variation in density with statistically significant higher values in November, minimum val- ues in January and intermediate values in April and July (one-way ANOVA; $F=6.28 \mathrm{p}<0.01$ for $P$. magellanicus, and $\mathrm{F}=7.32 \mathrm{p}<0.01$ for $P$. forceps; in both, critical $F_{4,56}[\alpha=0.01]=3.75$ ). The high density values, and the similarity of the variation pattern of both species with the total density values in the holdfast, indicate that these 2 species were the most important in the determination of the temporal overall density pattern of animals in the holdfasts of Macrocystis pyrifera. Halicarcinus planatus showed no temporal change in density, although its maximum density values also occurred in November. Anasterias antarctica and the polychaetes showed hardly detectable and not significant changes in time, without exhibiting a clear-cut temporal cycle.

In summary, the above data indicate that 3 out of the 5 taxa analysed achieve maximum densities in holdfasts of Macrocystis pyrifera during spring (November sampling). Only Anasterias antarctica and polychaetes - which comprise several species - do not conform to the general variation pattern, which encompasses a density of over $55 \%$ of the organisms in the holdfasts.

\section{Temporal variations of population structures}

The analysis of the mean linear dimensions of the 3 invertebrate species dominant in density in holdfasts of Macrocystis pyrifera showed that none of these 


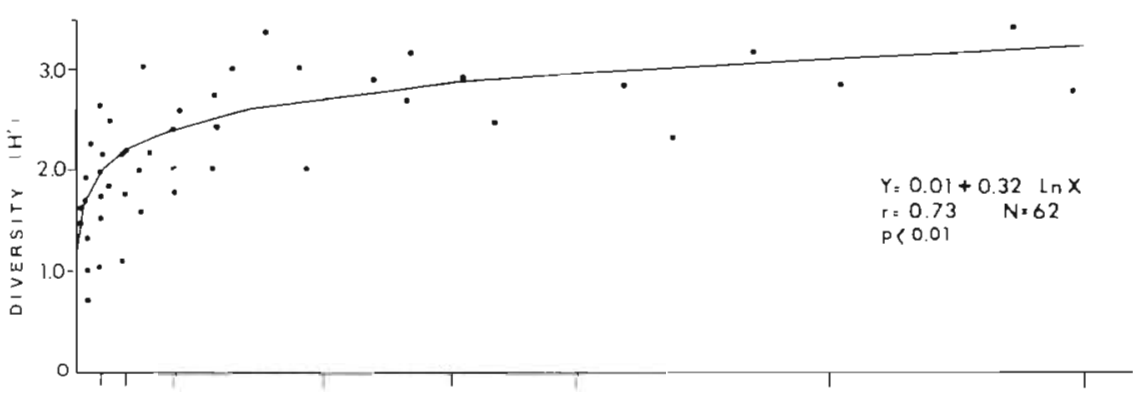

Fig. 2. Richness and diversity of species and numbers of individuals as a function of the holdfast volume in Macrocystis pyrifera individuals from Puerto Toro, Navarino Island
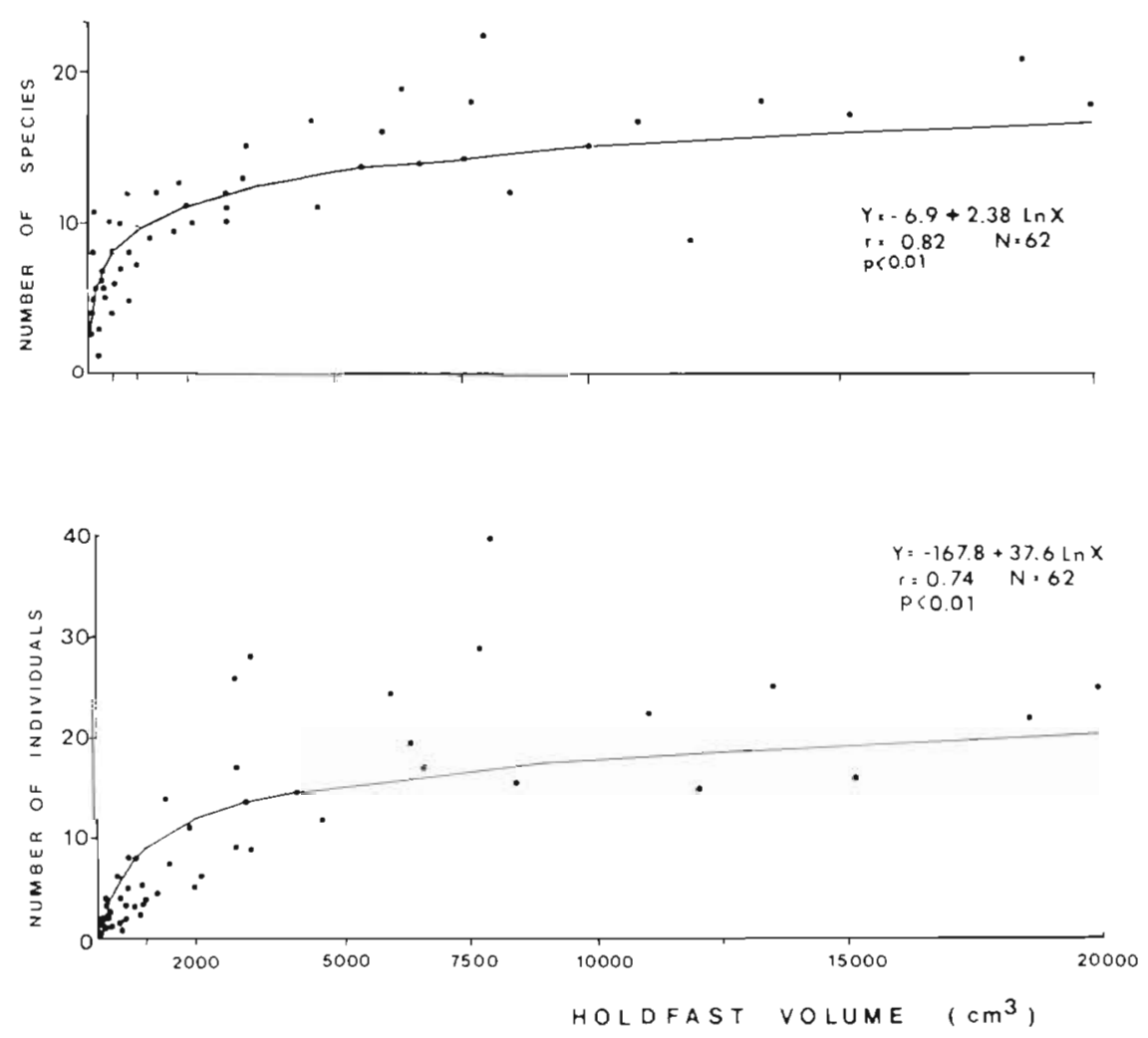

species exhibits important temporal variations in population structure as no significant differences were detected in their mean sizes (Fig. 5) or in size frequencies within the seasonal samples. Similarly, no significant changes were found in the average weight of the specimens in the populations of Pseudechinus magellanicus, Halicarcinus planatus and Pagurus forceps (Fig. 5). These results suggest that - at least in the most important species as the biomass and density - no temporal phenomena occur, either of growth or of juvenile recruitment, associated to the temporal changes in density and biomass previously reported (Fig. 4).

\section{Invertebrate occupation on the holdfast}

Fig. 6 shows the variation in mean biomass per holdfast of the 5 more abundant taxa at 6 size intervals of Macrocystis pyrifera holdfasts. The 5 taxa increased their biomass values with the size of holdfasts. These increments were most significant in holdfast volumes above $1000 \mathrm{~cm}^{3}$, mainly in Pseudechinus magellanicus, which reached the highest biomass values for this holdfast size. None of the taxa analysed fully disappeared along the size gradient of holdfasts.

Variation in relative importance (percentage of biomass) of the same 5 taxa at 6 size intervals of 

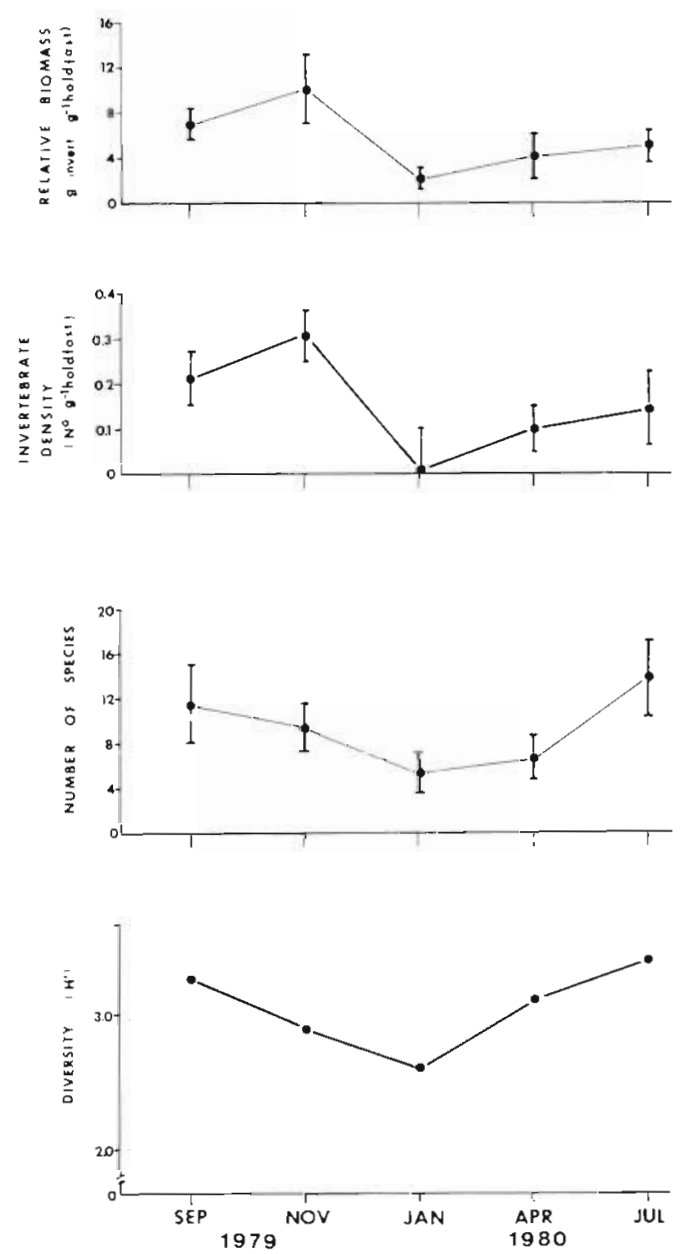

Fig. 3. Temporal variation in mean relative biomass, number of individuals, number of species and diversity $\left(\mathrm{H}^{\prime}\right)$ of invertebrates inside holdfasts of Macrocystis pyrifera at Puerto Toro, Navarino Island

holdfast volume revealed (Fig. 7) that the most important components in small holdfasts $\left(0\right.$ to $\left.50 \mathrm{~cm}^{3}\right)$ are several species of polychaetes. Holdfasts with volumes between 50 and $100 \mathrm{~cm}^{3}$ have large numbers of Halicarcinus planatus, Pagurus forceps and Anasterias antarctica; over $100 \mathrm{~cm}^{3}$, they contain increasing numbers of Pseudechinus magellanicus, relatively constant numbers of $A$. antarctica, and decreasing numbers of $H$. planatus and polychaetes. Thus, as holdfasts grow, there is an orderly process of replacement in the relative importance of these species. In no way do these changes represent species replacements, since the holdfast habitat to be colonized is subject to steady growth with time. Hence the peculiar morphology and growth pattern of holdfasts of Macrocystis pyrifera somehow condition their occupation as a function of time. Small holdfasts have few haptera arranged in a compact manner; they are mainly occupied by vermiform invertebrates. Older holdfasts are larger; their

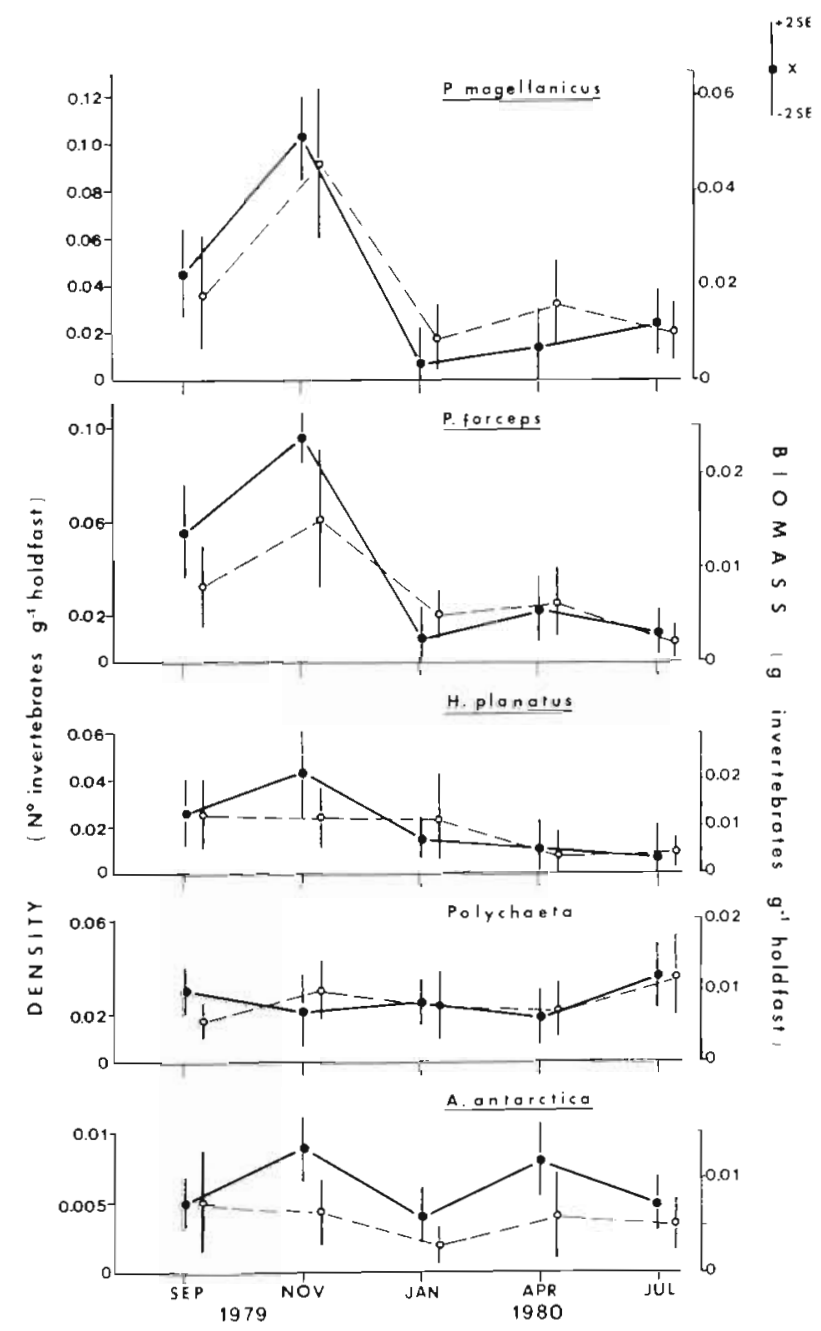

Fig. 4. Temporal variation in mean biomass (open circles) and density (closed circles) of the 5 most important invertebrate taxa occurring in holdfast of Macrocystis pyrifera, at Puerto Toro, Navarino Island

internal space within the haptera is normally occupied also by sea urchins and starfishes.

\section{DISCUSSION}

Between the fauna in holdfasts of Macrocystis pyrifera in the Beagle Channel and that reported for holdfasts of the same algae in the northern hemisphere, substantial differences exist. In California, over 100 invertebrate taxa occur in $M$. pyrifera holdfasts, mainly amphipods, polychaetes and isopods (Ghelardi, 1971). The fauna associated with $M$. pyrifera in southern Chile is about half as diversified; the most abundant taxa are echinoids and decapod crustaceans. Even though we did not identify the species of polychaetes and amphipods in this study, we could recognize close 


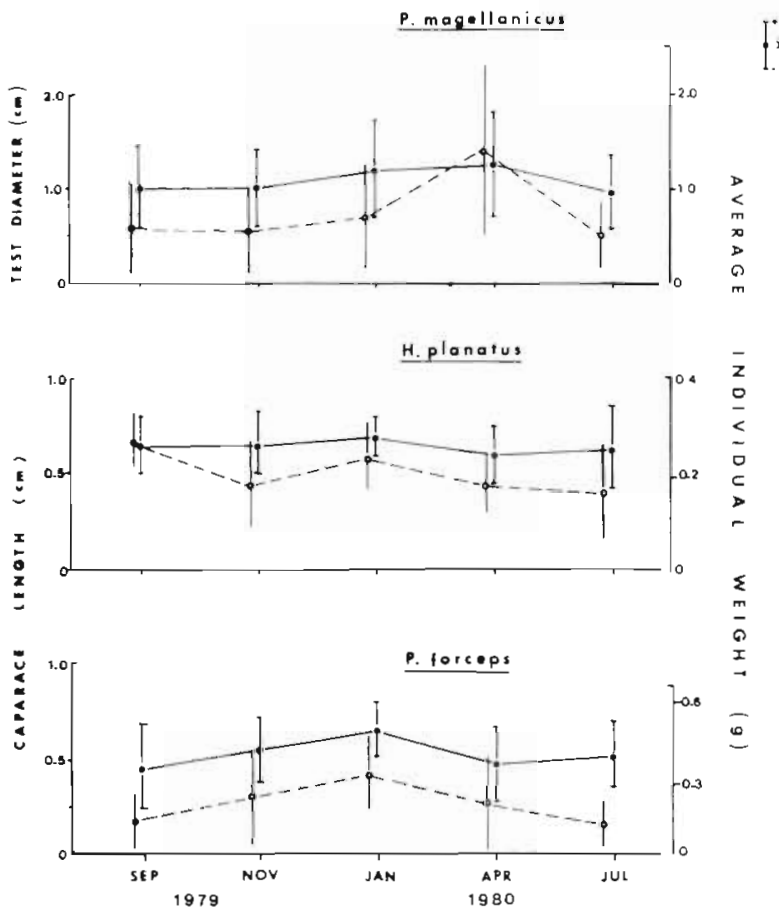

Fig. 5. Mean body dimension (closed circles) and average individual weight (open circles) of Pseudechinus magellanicus, Halicarcinus planatus and Pagurus forceps in 5 temporal samples

to 10 different taxa of polychaetes and 6 of amphipods. The addition of these taxa does not significantly reduce the marked difference in species richness between southern California and southern Chile.

These differences in the composition of the fauna cannot be ascribed solely to differences in size and volume between the holdfasts analysed by Ghelardi (1971), of a greater mean volume, and those studied in the present paper. Our study indicates that species richness and diversity depend on the volume of the holdfast only in relatively small plants. In larger plants, these parameters become independent of the volume. Consequently, the difference between southern California and southern Chile in faunistic composition and in the number of species occurring in holdfasts of Macrocystis pyrifera may be due to biogeographic and historical causes (Santelices, 1980).

The holdfasts of Macrocystis pyrifera studied showed significant temporal changes in abundance of animals (biomass and density) and richness of species. Maximum abundance of animals was observed in spring, the minimum in summer. On the other hand, maximum diversity and richness of species was reached in winter and minimum values occurred in summer. This implies that the general pattern of temporal change for animal abundance is determined by a few species whose temporal changes strongly affect

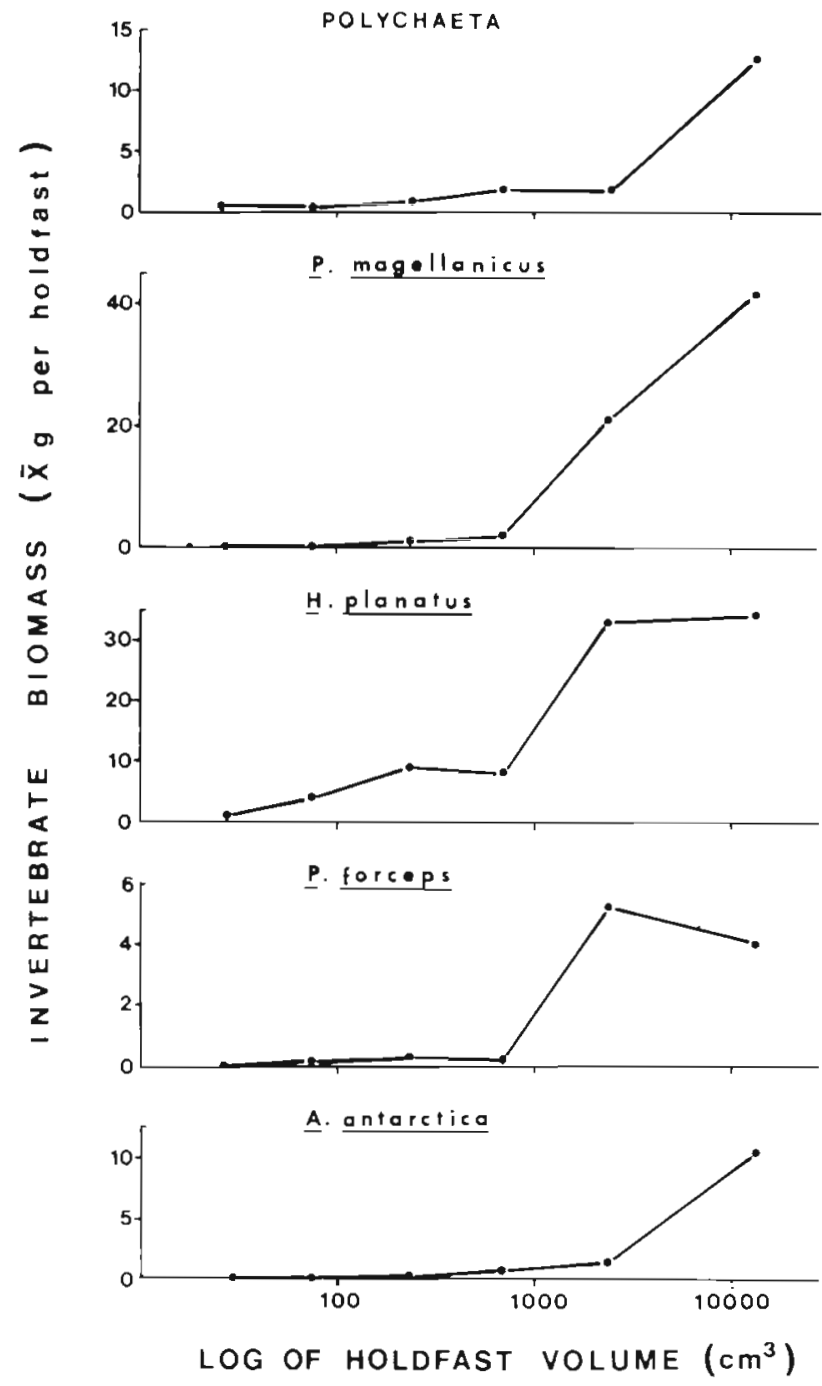

Fig. 6. Increments in invertebrate biomass of the 5 most abundant invertebrate taxa as function of kelp holdfast size

the total diversity (specifically affecting evenness); such species are Pseudechinus magellanicus and the hermit crab Pagurus forceps. These phenomena of ternporal variation have been traditionally associated with juvenile recruitment, migration, or individual growth. Our results, however, document neither juvenile recruitment nor individual growth, at least not for the most frequent and dominant taxa in $M$. pyrifera holdfasts. The data on individual size and biomass indicate that $M$. pyrifera holdfasts do not seem to play an important role as nursery grounds, which has been suggested for holdfasts of $M$. pyrifera in central California (Andrews, 1945), and in holdfasts of other brown algae elsewhere (Bayne, 1964; Wigham, 1975 Cancino and Santelices, 1981). Thus, the temporal variations we found may be primarily due to the migration behaviour of some of the dominant species. Such mi- 


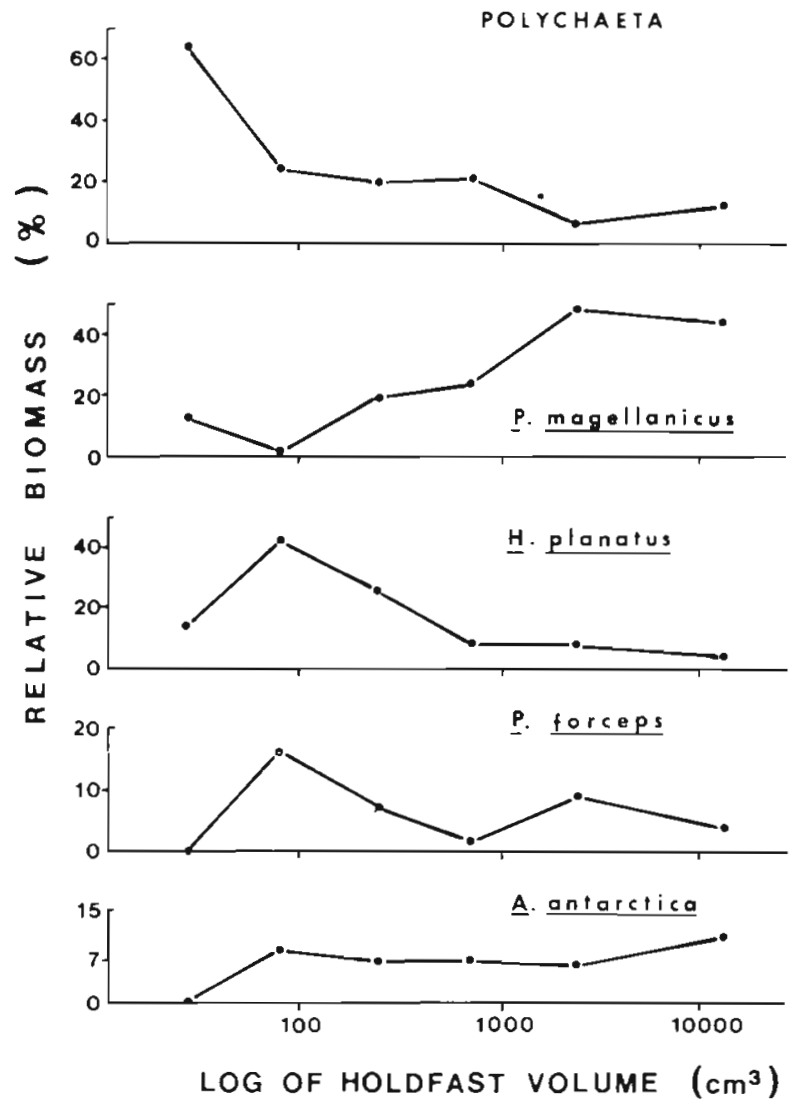

Fig. 7. Changes in relative importance (percentage of the biomass) of the most abundant invertebrate taxa in holdfasts of Macrocystis pyrifera at Puerto Toro, Navarino Island

grations to the inside of the holdfast in spring could be associated with reproduction phenomena related to encounters between males and females, or to the protection of embryos by oviparous females in decapod crustaceans. This would suggest that the holdfasts would serve as refuges for spawning (echinoids) or copulation (decapod crustaceans) in the first case, or as a shelter for oviparous females and their embryos in the second. Alternatively, urchins and hermit crabs may find refuge from winter/spring storms in the holdfasts, and wander out in the summer. We do not have additional data to discriminate between these 2 hypothesis.

The holdfasts of Macrocystis pyrifera studied - especially the smaller ones - reveal a clear pattern of invasion by invertebrate species. The process of colonization into the holdfast is not constant along the life span of the plant; it occurs very rapidly, primarily affecting early developmental stages of the holdfasts. As the holdfasts grow, the rate of colonization of new species decreases until reaching values near zero in larger holdfasts. The rapid colonization of holdfasts indicates that the source probably lies at a relatively short distance. The invertebrate fauna between holdfasts, and that within other, larger holdfasts of $M$. pyrifera must be the sources of colonization. Studies of communities between holdfasts, carried out at the same time and on the same forests of $M$. pyrifera as in the present work, disclosed that about 60 taxa exist in these sites (Santelices, Ojeda and Casanova, unpubl.). An analysis of this fauna showed that the species present are mostly the same as found in holdfasts. Considering that not all invertebrate species can invade holdfasts owing to size restrictions, approximately 47 of the 60 taxa are potential occupants of the holdfasts; a similar number was found for species occurring in mature $M$. pyrifera holdfasts. Consequently, all species at the source region which can reach the holdfast do so especially during the earlier developmental stages of the holdfast. Thereafter the rate of addition of species is reduced as most species present in the source region have already reached the holdfast.

Perhaps the most important generalization emerging from studies of holdfast occupation by invertebrates is that the dynamics of species turnover does not parallel the species replacement described for typical colonization processes of non-growing habitats (Sutherland, 1974; Connell and Slatyer, 1977). As in Lessonia nigrescens (Cancino and Santelices, 1981), pioneer species invading the holdfasts of Macrocystis pyrifera (polychaetes and Halicarcinus planatus) are consistently present in the holdfast community; as the holdfast grows, the invasion of new species does not appear to affect the populations of the earlier arrivers. Only a change in relative importance is observed. Even though this process has been shown so far only in a few Laminariales it seems to be a common phenomenon among invertebrate communities invading holdfasts of kelp-like species, as well as other colonizable substrata that grow, such as sponges, coral reefs, bushes and trees.

Acknowledgements. This paper is part of a comprehensive study on the biology and utilization of Macrocystis pyrifera in southern Chile. The work was financed through a Research Grant agreed on between the Armada de Chile and the Pontificia Universidad Católica de Chile. We thank R. Bravo, G. Casanova, J. C. Castilla, H. Castillo, A. Jullian, A. Larrea, C. Moreno and J. Vásquez for much help in the field, and J. Pearse for critically reading the manuscript.

\section{LITERATURE CITED}

Andrews, H. L. (1945). The kelp beds of the Monterrey region. Ecology 26: 24-37

Barrales, H. L., Lobban, C. S. (1975). The comparative ecology of Macrocystis pyrifera with emphasis on the forest of Chubut, Argentina. J. Ecol. 63: 657-677 
Bayne, B. L. (1964). Primary and secondary settlement in Mytilus edulis L. (Mollusca). Anim. Ecol. 33: 513-523

Cancino, J., Santelices, B. (1981). The ecological importance of kelp-like holdfasts as a habitat of invertebrates in Central Chile. II. Factors affecting community organization. Proceedings of the International Symposium 10, Sweden, p. 241-246

Colman, J. (1940). On the faunas inhabiting intertidal seaweeds. J. mar. Biol. Ass. U.K. 24: 129-183

Connell, J. H. Slatyer, R. (1977). Mechanisms of succession in natural communities and their role in community stability and organization. Am. Nat. 111: 1119-1144

Dayton, P. K. (1974). Kelp communities of southern South America. Antarct. J. U.S. 9: 22-23

Ghelardi, R. J. (1960). Structure and dynamics of the animal community found in Macrocystis pyrifera holdfasts. Ph. D. thesis, University of California, La Jolla

Ghelardi, R. J. (1971). Species structure of the holdfast community. In: North, W. J. (ed.) The biology of giant kelp beds (Macrocystis) in California. Nova Hedwigia 32: $381-420$

Jones, D. J. (1971). Ecological studies on macro-invertebrate populations associated with polluted kelp forest in the North Sea. Helgoländer wiss. Meeresunters. 22: 417-441

Jones, D. J. (1972). Changes in the ecological balance of invertebrate communities in kelp holdfast habitats of some polluted North Sea waters. Helgoländer wiss. Meeresunters. 23: 248-266

Jones, D. J. (1973). Variation in the trophic structure and species composition of some invertebrate communities in polluted kelp forest in the North Sea. Mar. Biol. 20: 351-365

Moore, P. G. (1971). The nematode fauna associated with holdfast of kelp (Laminaria hyperborea) in North East Britain. J. mar. Biol. Ass. U.K. 51: 589-604

Moore, P. G. (1972). Particulate matter in the sublittoral zone of an exposed coast and its ecological significance with special reference to the fauna inhabiting kelp holdfast. J. exp. mar. Biol. Ecol. 10: 59-80

Moore, P. G. (1973a). The larger crustacea associated with holdfast of kelp (Laminaria hyperborea) in Northeast Britain. Cah. Biol mar. 14: 493-518

Moore, P. G. (1973b). The kelp fauna of Northeast Britain. I. Introduction and the physical environment. J. exp. mar Biol. Ecol. 13: $97-125$

Moore, P. G. (1973c). The kelp fauna of Northeast Britain. II. Multivariate classification; turbidity as an ecological factor. J. exp. mar. Biol. Ecol. 13: 127-163

Moore, P. G. (1974). The kelp fauna of Northeast Britain. III. Qualitative and quantitative ordinations, and the utility of a multivariate approach. J. exp. Mar. Biol. Ecol. 16: $257-300$

Moore, P. G. (1978). Turbidity and kelp holdfast amphipoda. I. Wales and S. W. England. J. exp. mar. Biol. Ecol. 32: 53-96

Quast, J. C. (1971). Fish fauna on the rocky inshore zone. In: North, W. J. (ed.) The biology of giant kelp beds (Macrocystis) in California. Nova Hedwigia 32: 481-508

Santelices, B. (1980). Phytogeographic characterization of the temperate coast of Pacific South America. Phycologia 19: $1-12$

Santelices, B., Ojeda, F. P. (1984). Population dynamics of coastal forests of Macrocystis pyrifera in Puerto Toro, Isla Navarino, Southern Chile. Mar. Ecol. Prog. Ser. 14: 175-183

Scorrat, D. J. (1961). The fauna of Laminaria holdfasts. Ph. D thesis, University of Wales

Sokal, R. R., Rholf, F. J. (1969). Biometry. W. H. Freeman and Co., San Francisco

Sutherland, J. P. (1974). Multiple stable points in natural communities. Am. Nat. 108: 859-873

Wigham, G. D. (1975). The biology and ecology of Rissoa parva (da Costa) (Gastropoda: Prosobranquia). J. mar. Biol. Ass. U. K. 55: 45-67

This paper was presented by Professor J. S. Pearse; it was accepted for printing on November 27, 1983 